\title{
RESP 1.247.098-MS (INFORMATIVO 604 STJ \\ - PUBLICADO EM 21 DE JUNHO DE 2017) \\ - SUBSISTÊNCIA OU NÃO DA SEPARAÇÃO \\ JUDICIAL APÓS O ADVENTO DA EMENDA \\ À CONSTITUIÇÃO N. 66/2010
}

Riccardo Marcori Varalli*

\section{SÍNTESE DO CASO}

A ação de separação judicial de cuja decisão ora trataremos foi ajuizada por ambos os cônjuges, de forma consensual, buscando a homologação pelo juízo das condições pactuadas entre os consortes, no tocante ao recebimento de pensão, regulação de visitas ao único filho menor, à partilha de bens e ao nome da cônjuge virago. ${ }^{1}$

O juízo de primeiro grau, por entender que a Emenda Constitucional $n^{\circ} 66 / 2010$ aboliu a figura da separação, concedeu prazo de 10 (dez) dias para que a parte adequasse o pedido.

Inconformados, os ora recorrentes interpuseram agravo deinstrumento, tendo sido mantida a decisão recorrida mediante decisão singular, a qual foi confirmada quando da apreciação do agravo interno com a seguinte ementa:

AGRAVO REGIMENTAL EM AGRAVO DE INSTRUMENTO RESERVA DE PLENÁRIO - INCONSTITUCIONALIDADE DO INC. III, ART. 1571 DO CC - PRELIMINAR REJEITADA - PEDIDO DE SEPARAÇÃO CONSENSUAL - EC 66/2010 - NOVA REDAÇÃO

\footnotetext{
* Mestrando em Direito pela PUC/SP.Pós-graduado em Direito Processual Civil pela PUC/SP. Professor universitário, leciona Direito Civil e Direito Processual Civil.

1 A integra da decisão pode ser obtida em: <https://ww2.stj.jus.br/processo/revista/inteiroteor/?num_registro=201100747870\&dt_publicacao $=16 / 05 / 2017>$ Acesso em 01/08/2017.
} 
AO § 6. ${ }^{\circ}$ DO ARTIGO 226 DA CF - RECURSO IMPROVIDO. Se a decisão recorrida, em nenhum momento declara expressamente a inconstitucionalidade de dispositivo de lei, tampouco afasta no todo ou em parte sua incidência, não há que se falar em nulidade por inobservância à Súmula Vinculante $\mathrm{n}^{\circ} 10$ do STF. Com a nova redação ao $\S 6$. $^{\circ}$ do artigo 226 da Constituição Federal, o casamento civil pode ser dissolvido pelo divórcio.

Em suas razões do recurso especial, os recorrentes sustentaram a negativa de vigência aos artigos 1.571 , III, 1.572 e seguintes, do Código Civil, em virtude da não extinção do instituto da separação com o advento da Emenda Constitucional $n^{\circ} 66 / 10$.

\section{A DECISÃO DO STJ}

A decisão do STJ ora analisada foi assim ementada:

RECURSO ESPECIAL. DIREITO CIVIL. FAMÍLIA. EMENDA CONSTITUCIONAL N ${ }^{\circ} 66 / 10$. DIVÓRCIO DIRETO. SEPARAÇÃO JUDICIAL. SUBSISTÊNCIA. 1. A separação é modalidade de extinção da sociedade conjugal, pondo fim aos deveres de coabitação e fidelidade, bem como ao regime de bens, podendo, todavia, ser revertida a qualquer momento pelos cônjuges (Código Civil, arts. 1571, III e 1.577). O divórcio, por outro lado, é forma de dissolução do vínculo conjugal e extingue o casamento, permitindo que os ex-cônjuges celebrem novo matrimônio (Código Civil, arts. 1571, IV e 1.580). São institutos diversos, com conseqüências e regramentos jurídicos distintos. 2. A Emenda Constitucional n ${ }^{\circ} 66 / 2010$ não revogou os artigos do Código Civil que tratam da separação judicial. 3. Recurso especial provido.

A essência do litígio está circunscrita à manutenção ou não do instituto da separação judicial no ordenamento pátrio após a promulgação da Emenda Constitucional n. ${ }^{\circ}$ 66/2010 que deu nova redação ao $\S 6^{\circ}$ do art. 226 da Constituição Federal. O referido parágrafo possuía a seguinte redação: 
O casamento civil pode ser dissolvido pelo divórcio, após prévia separação judicial por mais de um ano nos casos expressos em lei ou comprovada separação de fato por mais de dois anos.

Por força da Emenda Constitucional já citada, a redação atual do referido dispositivo legal ficou bem mais singela:

O casamento civil pode ser dissolvido pelo divórcio. ${ }^{2}$

A partir das premissas acima, resta analisar se a nova redação do $\S 6^{\circ}$ do art. 226 da Constituição Federal apenas eliminou o elemento tempo para o divórcio ou se extirpou a separação judicial do sistema jurídico brasileiro.

\section{ANÁLISE DA DECISÃO}

Preliminarmente, se faz necessário atentarmos para os $\S \S$ $1^{\circ}$ e $2^{\circ}$ do art. $2^{\circ}$ da Lei de Introdução às Normas do Direito Brasileiro que assim estabelecem:

Art. 2o Não se destinando à vigência temporária, a lei terá vigor até que outra a modifique ou revogue.

$\S 1$ o A lei posterior revoga a anterior quando expressamente o declare, quando seja com ela incompativel ou quando regule inteiramente a matéria de que tratava a lei anterior.

$\S 2$ A lei nova, que estabeleça disposições gerais ou especiais a par das já existentes, não revoga nem modifica a lei anterior. ${ }^{3}$

Analisando o artigo supramencionado, podemos desde logo afastar a revogação expressa, uma vez que a Emenda Constitucional $n^{\circ}$ 66/2010 nada mencionou expressamente

2 BRASIL, Constituição Federal. Disponivel em < http://www.planalto.gov.br/ccivil_03/constituicao/constituicao.htm> Acesso em 01/08/2017.

3 BRASIL, Decreto-Lei 4.657/1942- com redação dada pela Lei 12.376/2010 - Lei de Introdução às normas do Direito Brasileiro. Disponível em < http://www.planalto.gov.br/ccivil_03/decreto-lei/Del4657compilado.htm $>$ 
sobre a separação. Diante disso, resta saber se norma constitucional revogou por incompatibilidade a separação judicial. Isto é, se houve revogação na modalidade tácita.

A resposta da doutrina e da jurisprudência não foi unânime. Correntes antagônicas foram formadas.

Surpreendentemente, a corrente majoritária que defende o final da separação terminou derrotada no acórdão ora analisado. Esse é o entendimento do voto-vencido do Ministro Luis Felipe Salomão. No corpo do mesmo, o eminente julgador defende que a Emenda Constitucional n 66/2010 traz a aplicação plena da aplicação do princípio constitucional de Direito de Família denominado de "Princípio da facilitação da dissolução de casamento". ${ }^{4}$

Essa corrente afirma que toda a legislação infraconstitucional que rege a separação judicial não pode ter uma força normativa maior que a própria Constituição. Desta feita, se a EC 66/2010 retirou da Carta Magna a separação judicial não há como manter o instituto na legislação infraconstitucional. ${ }^{5}$

Sobre o tema, a festejada doutrinadora Maria Berenice Dias $^{6}$ defende que:

Com a aprovação da EC 66/10, a separação desapareceu do sistema jurídico. Ainda que permaneçam no Código Civil os dispositivos que regiam o instituto ( $C C 1.571$ a 1.578), tal não significa que persista a possibilidade de alguém buscar somente o "término" do casamento, quer judicial quer extrajudicialmente. Agora só é possivel pleitear a dissolução do casamento via divórcio.

Nadando nas mesmas águas, Paulo Lôbo expõe o raciocínio seguido pela maioria dos civilistas brasileiros:

4 FARIAS, Cristiano Chaves de; ROSENVALD, Nelson. Direito das Familias. $2^{a}$ Edição, Rio de Janeiro, Lúmen Juris, 2010, p. 47

5 PEREIRA, Rodrigo da Cunha. Divórcio. Teoria e Prática. $2^{\text {a }}$ Edição, Rio de Janeiro. Editora GZ, 2010,p. 29.

6 DIAS, Maria Berenice. Divórcio Já! Comentários à Emenda Constitucional 66, de 13 de julho de 2010. São Paulo: Revista dos Tribunais, 2010, p. 128

110 - Revista do Curso de Direito da Faculdade de Humanidades e Direito,

v. 14, n. 14, Edição Especial 2017 
Como se demonstrou, a inserção constitucional do divórcio evoluiu da consideração como requisito prévio ao divórcio até sua total desconsideração. Em outras palavras, a Constituição deixou de tutelar a separação judicial. (...) Portanto, não sobrevive qualquer norma infraconstitucional que trate da dissolução da sociedade conjugal isoladamente, por absoluta incompatibilidade com a Constituição, de acordo com a redação atribuída pela PEC do Divórcio. A nova redação do $\S 6^{\circ}$ do art. 226 da Constituição apenas admite a dissolução do vínculo conjugal. (...). No direito brasileiro, há grande consenso doutrinário e jurisprudencial acerca da força normativa própria da Constituição.Sejam as normas constitucionais regras ou princípios não dependem de normas infraconstitucionais para estas prescreverem o que aquelas já prescreveram. A nova redação do $\S 6^{\circ}$ do art. 226 da Constituição qualifica-se como norma-regra, pois seu suporte fático é precisamente determinado: o casamento pode ser dissolvido pelo divórcio, sem qualquer requisito prévio, por exclusivo ato de vontade dos cônjuges.

Continua o mencionado autor:

Ainda que se admitisse a sobrevivência da sociedade conjugal, a nova redação da norma constitucional permite que os cônjuges alcancem suas finalidades, com muito mais vantagem. Por outro lado, entre duas interpretações possíveis, não poderia prevalecer a que consultasse apenas o interesse individual do cônjuge que desejasse instrumentalizar a separação para o fim de punir o outro, comprometendo a boa administração da justiça e a paz social. É da tradição de nosso direito o que estabelece o art. $5^{\circ}$ da Lei de Introdução ao Código Civil: na aplicação da lei, o juiz atenderá aos fins sociais a que ela se dirige e às exigências do bem comum. O uso da justiça para punir o outro cônjuge não atende aos fins sociais nem ao bem comum, que devem iluminar a decisão judicial sobre os únicos pontos em litígio, quando os cônjuges sobre eles não transigem: a guarda e a proteção dos filhos menores, os alimentos que sejam devidos, a continuidade ou não do nome de casado e a partilha dos bens comuns. ${ }^{7}$

7 LÔBO, Paulo Luiz Neto. Revista Brasileira de Direito das Famílias e Sucessões, ago-set de 2009, ano XI, n 11. 
Ainda, no mesmo sentido, pensam Flavio Tartuce ${ }^{8}$ e Rolf Madaleno ${ }^{9}$ e Álvaro Villaça Azevedo. ${ }^{10}$

A jurisprudência do Superior Tribunal de Justiça, antes do acórdão em comento, também considerava que o instituto da separação judicial havia sido extinto:

PROCESSUAL CIVIL. CIVIL. RECURSO ESPECIAL. FAMÍLIA. AÇÃO DE DIVÓRCIO CONSENSUAL DIRETO. AUDIÊNCIA PARA TENTATIVA DE RECONCILIAÇÃO OU RATIFICAÇÃO. INEXISTÊNCIA. DIVÓRCIO HOMOLOGADO DE PLANO. POSSIBILIDADE. RECURSO DESPROVIDO. 1.Em razão da modificação do art. 226, $\S 6^{\circ}$, da $\mathrm{CF}$, com a nova redação dada pela EC $66 / 10$, descabe falar em requisitos para a concessão de divórcio. 2. Inexistindo requisitos a serem comprovados, cabe, caso o magistrado entenda ser a hipótese de concessão de plano do divórcio, a sua homologação. 3. A audiência de conciliação ou ratificação passou a ter apenas cunho eminentemente formal, sem nada produzir, e não havendo nenhuma questão relevante de direito a se decidir, nada justifica na sua ausência, a anulação do processo. 4. Ainda que a $\mathrm{CF} / 88$, na redação original do art. 226, tenha mantido em seu texto as figuras anteriores do divórcio e da separação e o CPC tenha regulamentado tal estrutura, com a nova redação do art. 226 da CF/88, modificada pela EC 66/2010, deverá também haver nova interpretação dos arts. 1.122 do CPC e 40 da Lei do Divórcio, que não mais poderá ficar à margem da substancial alteração. Há que se observar e relembrar que a nova ordem constitucional prevista no art. 226 da Carta Maior alterou os requisitos necessários à concessão do Divórcio Consensual Direto.5. Não cabe, in casu, falar em inobservância do Princípio da Reserva de Plenário, previsto no art. 97 da Constituição Federal, notadamente porque não se procedeu qualquer declaração de inconstitucionalidade,

8 TARTUCE, Flávio. Direito civil: direito de familia, v.5. Rio de Janeiro: Forense, 2017, p. 205-231

9 MADALENO, Rolf. Curso de direito de família. Rio de Janeiro: Forense, 2015, p. 213-222

10 AZEVEDO, Álvaro Villaça. Emenda constitucional do divórcio. Revista Magister de Direito Civil e Processual Civil, Porto Alegre, n. 39, p. 88-96, nov/dez. 2010.

112 - Revista do Curso de Direito da Faculdade de Humanidades e Direito,

v. 14, n. 14, Edição Especial 2017 
mas sim apenas e somente interpretação sistemática dos dispositivos legais versados acerca da matéria. 6. Recurso especial a que se nega provimento. (REsp 1483841/RS, Rel. Ministro MOURA RIBEIRO, TERCEIRA TURMA, julgado em 17/03/2015, DJe 27/03/2015)

No entanto, a corrente vencedora, embora menos aceita pelos doutrinadores, foi no sentido de que o instituto da separação judicial não foi revogado, conforme entendimento da Ministra Maria Isabel Gallotti (relatora da decisão em comento) e dos Ministros Antonio Carlos Ferreira, Marco Buzzi e Raul Araújo.

Essa parcela de estudiosos entende que a separação judicial persiste em nosso sistema jurídico, sendo faculdade do casal optar pelo manejo da separação judicial ou do divórcio, conforme sua vontade, prestigiando-se a autonomia e liberdade quanto ao assunto.

Neste sentido lecionam José Moacyr Doretto Nascimento e Gustavo Gonçalves Cardozo:

É de se indagar se a separação judicial foi, deveras, extirpada do ordenamento jurídico pela superveniência constitucional. A novel norma constitucional preceitua que o casamento será extinto pelo divórcio, silenciando-se quanto à separação; nada diz, nada prescreve. Lança-se, nesse contexto, outra indagação retórica: o casal que passe por crise familiar, querendo buscar um respiradouro, deverá divorciar-se açodadamente ou viver em ligeira ilegalidade, que constrange socialmente muitos, uma vez que presente ainda o dever de fidelidade reciproca? (...) Há que se respeitar a vontade dos individuos, ainda incertos quanto ao futuro, mas decididos quanto ao presente. Há que se viabilizar e reconhecer a persistência da separação consensual em nosso sistema. Nem se venha redargüir que serão esses casos poucos ou mesmo raros, porque o direito, em sua modernidade, também tutela e promove a felicidade de minorias. ${ }^{11}$

11 NASCIMEnTO, José Moacyr Doretto e CARDOZO, Gustavo Gonçalves. A emenda do divórcio: singelas reflexões. Disponivel em $<\underline{\text { https://jus. }}$ com.br/artigos/17011/a-emenda-do-divorcio-singelas-reflexoes. Acesso em $01 / 08 / 2017>$ (sem grifos no original) 
Sustentando a permanência da separação após a Emenda 66/2010, Yussef Said Cahali continua defendendo que divórcio e separação judicial são institutos autônomos e distintos: o primeiro com disciplina (a partir de 1934) necessariamente de natureza constitucional; o segundo, desde a Lei do Matrimônio Civil, com sua disciplina exaurida em sede infraconstitucional ${ }^{12}$.

A Ministra Relatora Maria Isabel Galotti analisou a literalidade do artigo previsto na Constituição e concluiu que somente houve a supressão do requisito temporal de dois anos, bem como do sistema bifásico (que exigia a separação para depois converter em divórcio). O julgado entendeu que permanece a opção das partes pela separação judicial ou consensual, para reflexão e decisão ponderada do casal.

Regina Beatriz Tavares da Silva, assim se manifesta sobre o tema:

Essa norma da CF (Art. 226) é formalmente e não materialmente constitucional; ali não são reguladas as espécies de dissolução conjugal, que se mantêm no Código Civil, sem quaisquer pressupostos temporais, mas com a preservação dos efeitos diversos de cada uma dessas espécies. ${ }^{13}$

E, continua a conceituada civilista, invocando preceitos constitucionais para defender a manutenção da separação judicial:

A manutenção da separação decorre do respeito aos direitos fundamentais, dentre os quais se destaca a liberdade na escolha na espécie dissolutória do casamento ( $\mathrm{CF}$ art. $5^{\circ}$ caput). Dissolvida a sociedade conjugal pela separação, pode ser restabelecido o mesmo casamento (CC artigo 1.577), o que não ocorre no divórcio, que dissolve o vínculo conjugal, devendo

${ }^{12}$ CAHALI, Yussef Said. Separações Conjugais e Divórcio: da obra Divórcio e Separação, revista, ampliada e atualizada com a EC 66/2010 (Emenda do Divórcio). 12. ed. São Paulo: Revista dos Tribunais, 2011, p. 76.

${ }^{13}$ SILVA, Regina Beatriz Tavares da. Divórcio e Separação: após a EC n. 66/2010. 2. ed. São Paulo: Saraiva, 2012, p. 127. 
ser preservada a liberdade dos cônjuges na escolha dessa espécie dissolutória. E, exatamente por ser o Brasil um Estado laico, é inviolável a liberdade de consciência e de crença e de exercício de direitos em razão de crença ( $\mathrm{CF}$ art. $5^{\circ}$ VI e VIII); a supressão da separação violaria a liberdade no exercício do direito de regularização do estado civil dos que têm crença que não admite o divórcio, já que deveriam manter-se separados somente de fato e não de direito, o que, além disso, acarretaria insegurança jurídica pela zona cinzenta da separação de fato. Em respeito à dignidade da pessoa humana e à tutela dos direitos fundamentais à vida, à integridade física e psíquica e à honra, assim como à proteção especial aos membros da família e ao combate à violência doméstica ( $\mathrm{CF}$ artigo $1^{\circ}$ III, $5^{\circ}$ caput, III e X, artigo 226, caput e parágrafo $8^{\circ}$ ) as espécies dissolutória sanção - baseada no grave descumprimento de dever conjugal (CC artigo 1.572, caput e artigo 1.573) - e dissolutória remédio - causada pela doença mental do cônjuge (CC artigo 1572, parágrafo $2^{\circ}$ ) - , permanecem vigentes e reguladas no Código Civil, ao lado da espécie baseada na mera impossibilidade da vida em comum. Somente na espécie "dissolutória sanção" ocorre a perda do direito à pensão plena do cônjuge que violou gravemente dever conjugal (CC artigo 1704) e ao sobrenome conjugal (CC artigo 1.578), e apenas na espécie "dissolutória remédio" existe proteção patrimonial ao enfermo. ${ }^{14}$

Tal entendimento ganhou ainda mais força quando a $\mathrm{V}$ Jornada de Direito Civil, no Conselho da Justiça Federal, aprovou o Enunciado 514: “A EC 66/2010 não extinguiu a separação judicial e extrajudicial”. Sendo apresentada a seguinte justificativa: A Emenda Constitucional 66/2010 alterou o artigo 226, parágrafo $6^{\circ}$ da Constituição Federal e facilitou o divórcio ao eliminar seus requisitos temporais, sem, contudo, eliminar os institutos da separação e da conversão da separação em divórcio.

14 SILVA, Regina Beatriz Tavares da. EC 66 não extinguiu separação judicial e extrajudicial. Disponível em <http://www.conjur.com.br/2011-nov-12/ec-662010-nao-extinguiu-separacao-judicial-extrajudicial>. Acesso no dia $01 / 08 / 2017$ 
Ora, com efeito, como disse a própria Relatora no julgamento do acórdão comentado: "Quem pode o mais, pode o menos". Não faz sentido nenhum ser dada a oportunidade do cidadão se divorciar de maneira direta e proibi-lo de manejar a separação judicial.

No mesmo sentido, Laune Andrekowisk Volpe Camargo defende que as normas infraconstitucionais que fazem referência à separação judicial não apresentam qualquer antinomia com a redação constitucional do artigo 226 da Constituição Federal, pois a separação judicial não contraria o divórcio. E assim arremata a referida autora:

Extirpar a separação judicial é ferir o princípio da continuidade, já que a dissolução da sociedade conjugal sempre existiu no Brasil, de modo que não é crivel que o legislador constituinte, sem realizar uma audiência pública, sem sequer debater tal efeito entre seus pares, tenha rompido um sistema fundado em normas infraconstitucionais, objetivando proibir que casais optem pela dissolução da sociedade conjugal através da separação facultativa. Com todo respeito a quem pensa diversamente, isso seria um atentado não só a Constituição, mas a democracia, pois deixaria o sistema em um enorme vácuo jurídico. Assim, resta demonstrado que a Emenda Constitucional 66/2010 não extinguiu a separação jurídica, pois ao extirpar do sistema apenas os condicionantes do divórcio observou o princípio da continuidade, ou seja, trouxe o novo, o necessário, sem com isso, retirar o que não interfere na inovação pretendida. ${ }^{15}$

Por fim, a corrente ficou ainda mais fortalecida com a entrada em vigor do Novo Código de Processo Civil ${ }^{16}$, uma

${ }^{15}$ CAMARGO, Lauane Andrekowisk Volpe. O projeto do Novo Código de Processo Civil e o instituto da separação judicial consensual. In: FREIRE, Alexandre; DANTAS, Bruno; NUNES, Dierle; DIDIER JR., Fredie; MEDINA, José; FUX, Luiz; VOLPE, Luiz; MIRANDA, Pedro. (Orgs.) Novas tendências do Processo Civil. Salvador: jusPODIVM, 2014, p. 161

${ }^{16}$ Em palestra proferida na $47^{\text {a }}$ reunião do Fórum Permanente de Direito de Família e Sucessões, realizada no Auditório da Emerj no dia 16 de outubro de 2015, ocasião em que foi debatido o Direito de Família no Novo Código 
vez que este traz, em seu bojo, diversas referências à figura da separação judicial, trazendo ainda mais importância para esse remédio jurídico do Direito de Família.

\section{CONCLUSÃO}

O Direito de Família Contemporâneo é caracterizado pelo afeto enquanto um valor jurídico e pelo respeito da autonomia dos indivíduos diante da sua vida particular.

O Supremo Tribunal Federal, após o advento da Emenda Constitucional $n^{\circ} 66 / 10$, teve a oportunidade de debater sobre o competência da ação de separação reforçando a tese da permanência deste importante instituto no ordenamento jurídico brasileiro.

Entendemos que o acórdão analisado, de maneira salutar, consagra o princípio da intervenção mínima do Direito de Família, que determina que o Estado não pode estabelecer paradigmas e conceitos fechados no direito de família. Muito pelo contrário, deve permitir a liberdade de escolha do casal, deixando com que ele opte pelo divórcio ou pela separação, conforme sua vontade.

Não se vislumbra qualquer conflito entre regras ou princípios com a permanência do instituto da separação judicial. $\mathrm{Na}$ verdade, trata-se de reconhecer a autonomia do casal para decidir a respeito da sua vida privada, sem determinação ou interferência do Estado na privacidade. Trata-se de reconhecer que o texto constitucional, neste tema, privilegiou a autonomia e vontade das partes. Muito embora se possa argumentar que na prática os casais prefiram o divórcio direito, a previsão legislativa expressa garante o poder de escolha.

de Processo Civil, o Professor Fredie Didier Júnior posicionou-se no sentido de que o instituto da separação judicial não foi eliminado do Direito Brasileiro e ainda foi reafirmado pela nova legislação processual civil, que trata expressamente do procedimento da separação judicial nos artigos 693 a 699 e 731 a 734, além de dedicar a separação em diversas outras normas, como as que tratam de jurisdição e competência, por exemplo. 


\section{REFERENCIAS}

AZEVEDO, Álvaro Villaça. Emenda constitucional do divórcio. Revista Magister de Direito Civil e Processual Civil, Porto Alegre, n. 39, p. 88-96, nov/dez. 2010.

BRASIL, Constituição Federal. Disponivel em < http://www.planalto.gov.br/ccivil_03/constituicao/constituicao.htm

BRASIL, Decreto-Lei 4.657/1942 - com redação dada pela Lei 12.376/2010 - Lei de Introdução às normas do Direito Brasileiro. Disponível em < http:// www.planalto.gov.br/ccivil_03/decreto-lei/De14657compilado.htm>

BRASIL, SUPERIOR TRIBUNAL DE JUSTIÇA, REsp 1.247.098-MS - Subsistência ou não da separação judicial após o advento da Emenda à Constituição n. 66/2010.Disponível em :< https://ww2.stj.jus.br/processo/revista/ inteiroteor $/$ ?num_registro=201100747870\&dt_publicacao=16/05/2017>

CAHALI, Yussef Said. Separações Conjugais e Divórcio: da obra Divórcio e Separação, revista, ampliada e atualizada com a EC 66/2010 (Emenda do Divórcio). 12. ed. São Paulo: Revista dos Tribunais, 2011.

CAMARGO, Lauane Andrekowisk Volpe. O projeto do Novo Código de Processo Civil e o instituto da separação judicial consensual. In: FREIRE, Alexandre; DANTAS, Bruno; NUNES, Dierle; DIDIER JR., Fredie; MEDINA, José; FUX, Luiz; VOLPE, Luiz; MIRANDA, Pedro. (Orgs.) Novas tendências do Processo Civil.Salvador: jusPODIVM, 2014.

DIAS, Maria Berenice. Divórcio Já! Comentários à Emenda Constitucional 66, de 13 de julho de 2010. $1^{\text {a }}$ Edição, São Paulo. Editora Revista dos Tribunais, 2010.

FARIAS, Cristiano Chaves de; ROSENVALD, Nelson. Direito das Familias. 2. ed. Rio de Janeiro: Lumen Juris, 2010.

LÔBO, Paulo Luiz Neto. Revista Brasileira de Direito das Famílias e Sucessões, ago-set de 2009, ano XI, nº 11 .

MADALENO, Rolf. Curso de direito de familia. Rio de Janeiro: Forense, 2015.

NASCIMEnTO, José Moacyr Doretto e CARDOZO, Gustavo Gonçalves. A emenda do divórcio: singelas reflexões. Disponível em $\leq \mathrm{https}$ ://jus.com. br/artigos / 17011/a-emenda-do-divorcio-singelas-reflexoes. $\geq$

PEREIRA, Rodrigo da Cunha. Divórcio. Teoria e Prática. 2. ed. Rio de Janeiro: GZ, 2010.

118 - Revista do Curso de Direito da Faculdade de Humanidades e Direito,

v. 14, n. 14, Edição Especial 2017 
SILVA, Regina Beatriz Tavares da. Divórcio e Separação: após a EC n. 66/2010. 2. ed. São Paulo: Saraiva, 2012.

nivel em:

EC 66 não extinguiu separação judicial e extrajudicial. Dispo-

<http: / / www.conjur.com.br/2011-nov-12/ec-662010-nao-extinguiu-separacao-judicial-extrajudicial $>$.

TARTUCE, Flávio. Direito civil: direito de familia, v. 5. Rio de Janeiro: Forense, 2017.

RECURSO ESPECIAL No 1.247.098 - MS (2011/0074787-0)

RELATORA : MINISTRA MARIA ISABEL GALLOTTI

RECORRENTE: J S DE A E OUTRO

\section{EMENTA}

RECURSO ESPECIAL. DIREITO CIVIL. FAMÍLIA. EMENDA

CONSTITUCIONAL N 66/10. DIVÓRCIO DIRETO. SEPARAÇÃO JUDICIAL. SUBSISTENCIA.

1. A separação é modalidade de extinção da sociedade conjugal, pondo fim aos

deveres de coabitação e fidelidade, bem como ao regime de bens, podendo, todavia, ser revertida a qualquer momento pelos cônjuges (Código Civil, arts. 1571, III e 1.577). O divórcio, por outro lado, é forma de dissolução do vínculo conjugal e extingue o casamento, permitindo que os ex-cônjuges celebrem novo matrimônio (Código Civil, arts. 1571, IV e 1.580). São institutos diversos, com conseqüências e regramentos jurídicos distintos.

2. A Emenda Constitucional n 66/2010 não revogou os artigos do Código Civil que tratam da separação judicial.

3. Recurso especial provido.

\section{ACÓRDÃo}

Prosseguindo no julgamento, após o voto-vista do Ministro Luis Felipe Salomão negando provimento ao recurso especial, divergindo da relatora, e os votos dos Ministros Antonio Carlos Ferreira, Marco Buzzi e Raul Araújo acompanhando a relatora, a Quarta Turma, por maioria, deu provimento ao recurso especial, nos termos do voto da relatora. Vencido o Ministro Luis Felipe Salomão. Os Srs. Ministros Antonio Carlos Ferreira, Marco Buzzi e Raul Araújo votaram com a Sra. Ministra Relatora.

Brasília (DF), 14 de março de 2017(Data do Julgamento)

\section{MINISTRA MARIA ISABEL GALLOTTI}

Relatora 